\section{Dissecting the Behavior of a Promiscuous Solvate Former**}

\author{
Christopher P. Price, Gary D. Glick, and \\ Adam J. Matzger*
}

Solvate formation is a common occurrence among organic, organometallic, and inorganic compounds. Its impact on the stability and bioavailability of pharmaceuticals has led to considerable investigation of solvated drug substances. ${ }^{[1]}$ Some compounds display indiscriminate solvate formation, while others are considerably more selective. Significantly, the structural features that lead to one behavior or another have not been identified. Hence, empirical approaches are required for the discovery of solvates. Two situations can

[*] C. P. Price, Prof. G. D. Glick, Prof. A. J. Matzger Department of Chemistry

University of Michigan

Ann Arbor, MI 48109-1055 (USA)

Fax: (+1) 734-615-8553

E-mail:matzger@umich.edu

[**] Supported in part by the National Institutes of Health Grant R01 Al47450. We thank GMP | Immunotherapeutics for samples of $\mathrm{Bz}-423$ and $\mathrm{Bz}-430$ and Jeff W. Kampf for the crystal structure determination.

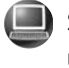
Supporting information for this article is available on the WWW under http://www.angewandte.org or from the author. readily be envisaged that would tend to favor solvate formation. First, compounds in which potential intermolecular interactions, such as hydrogen bonding, are not well satisfied in the unsolvated form generally incorporate solvent molecules to provide strong intermolecular interactions and often solvate selectively based on functionality. The other limiting case is solvent inclusion to decrease void space in the crystal. Most compounds have contributions from both of these driving forces, which can be viewed as lowering the crystal free energy primarily through electrostatic and van der Waals interactions, respectively.

Readily solvated pharmaceuticals have received attention in the literature, two prominent examples are sulfathiazole and gossypol. Sulfathiazole is an antibacterial sulfa-drug known to crystallize in over 100 solvates/cocrystals and five solvent-free polymorphs. ${ }^{[2-6]}$ It forms solvates with many solvents; however, there are some notable exceptions, which include hydrocarbon and halogenated solvents. Solvated sulfathiazole forms a diverse set of crystal structures, as well as several isostructural solvates. In some cases, the role of the solvent is to fill void space in the lattice (e.g., acetonitrile, dioxane), while in other crystals the solvent satisfies specific intermolecular interactions (e.g., $N$-formyl piperidine). Gossypol is a natural product that has been used as a male contraceptive and it forms solvates/cocrystals with nearly 100 molecules. ${ }^{[7]}$ Solvates can be generated from nearly every common organic solvent. It does, however, crystallize in a solvent-free form from ligroin and mixtures of hexane and diethyl ether. Like sulfathiazole, gossypol forms isostructural solvates, in which the solvent fills a cavity in the structure (e.g., carbon tetrachloride, $m$-xylene), as well as solvates with specific hydrogen-bonding interactions between gossypol and the included solvent (e.g., acetic acid, 2-propanol).

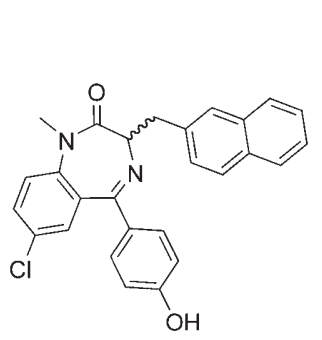

$\mathrm{Bz}-423$<smiles>CN1C(=O)[C@H](Cc2ccccc2-c2ccccc2)N=C(c2ccc(O)cc2)c2cc(Cl)ccc21</smiles>

$\mathrm{Bz}-430$<smiles>Nc1ccc(S(=O)(=O)N=c2[nH]ccs2)cc1</smiles>

sulfathiazole<smiles>Cc1cc2c(C(C)C)c(O)c(O)c(C=O)c2c(O)c1-c1c(C)cc2c(C(C)C)c(O)c(O)c(C=O)c2c1O</smiles>

gossypol<smiles>CC1(C)CC(C)(c2ccc(O)cc2)c2ccccc2O1</smiles>

Dianin's compound
To learn more about the factors that lead to solvate formation in pharmaceuticals, we investigated the crystallization of Bz-423, a 1,4-benzodiazepin-2-one. Bz-423 specifi- 
cally attenuates autoimmune disease in the best animal models of systemic lupus erythematosus. ${ }^{[8-10]}$ In the process of selecting a crystalline form for ultimate dosage, a remarkable property of this compound was revealed: all crystals of Bz-423 obtained from common solvents were solvates. Furthermore, solvents that did not lead to crystalline materials (e.g., acetone, benzene, diethyl ether, 2,2,4,4,6,8,8heptamethyl nonane, heptane, hexanes, pyridine, triethylamine, 2,2,4trimethylpentane, $\mathrm{CH}_{2} \mathrm{Cl}_{2}$, THF) yielded amorphous forms, typically with included solvent as judged by Raman spectroscopy.

Cocrystals of acetonitrile, acetic acid, dibutyl ether, ethanol, ethyl acetate, methanol, 1-propanol, 2-propanol, toluene, and 1,2,4-trichlorobenzene with Bz-423 were readily formed by evaporation from pure solution. Crystal structures of the acetonitrile, ethanol, ethyl acetate, 2-propanol, and acetic acid solvates were determined to ascertain whether these forms were isomorphous, perhaps with the solvent occupying channels or other regular vacancies in the lattice. ${ }^{[11]}$ However, these are structurally distinct with different modes of interaction between Bz-423 molecules and the solvent (Figure 1). The acetonitrile solvate, for example, forms hydrogen bonds with the phenolic hydroxy group of Bz-423, whereas ethanol and 2-propanol both accept a hydrogen bond from the hydroxy group and act as a donor with the carbonyl group of Bz-423. In contrast, ethyl acetate forms no strong hydrogen bonds with Bz-423. However, not all of the forms differ substantially in structure, carboxylic acids, including the Bz-423/acetic acid (1:1), the Bz-423/fumaric acid (2:1), and Bz-423/succinic acid (2:1) cocrystals, are isostructural with essentially identical hydrogen-bonding patterns (Figure 2), and each is nearly isostructural with the Bz-423/acetonitrile solvate (1:1). The Bz-423/ethanol (1:1) and Bz-423/2-propanol (1:1) solvates are also nearly isostructural, with both possessing identical hydrogen-bonding patterns.

To test the hypothesis that the particular combination of functionality found in Bz-423 drives the solvation behavior, the crystallization of Bz-430, which contains a biphenyl unit in place of the naphthalene ring, was scrutinized. This compound does not display a propensity toward solvate formation despite being crystallized from acetonitrile, benzene, ethyl acetate, methanol, $\mathrm{CH}_{2} \mathrm{Cl}_{2}$, and THF (see the Supporting
Information). This finding suggests that functionality-driven solvation, in which solvent inclusion is favored by enhanced satisfaction of intermolecular interactions, does not explain the observed behavior of Bz-423. In addition, Bz-423 cocrystallizes with a wide variety of solvents, with many different structures being formed, and displays an inability to form unsolvated crystals from common solvents. These observations suggest that Bz-423, in contrast to Bz-430, does not pack efficiently with itself.

One measure of how tightly a molecule packs in a crystal lattice is packing efficiency, measured by the packing coefficient $C_{\mathrm{k}} \cdot{ }^{[12]}$ This quantity reflects the percentage of void space in molecular crystals. A solvent-free reference form was required to assess the effect of solvent inclusion on the packing efficiency of Bz-423. This reference form was achieved by dissolving the Bz-423/methanol solvate in polyethylene glycol dimethyl ether $\left(x_{n}=11\right)$ at elevated temperature overnight to yield solvent-free single crystals. The packing coefficient of this structure was calculated using the equation developed by Kitaigorodskii. ${ }^{[13]}$ Because the packing coefficient relates the volume of the unit cell to the volume of molecules in the cell, the molecular volume of each nonequivalent molecule in the crystal must be calculated. ${ }^{[14]}$ The volume of each isolated species was determined for the solvates and then added together according to stoichiometry.

Consistent with the notion of inefficient packing in the unsolvated form, the packing coefficients of the Bz-423 solvate structures, as well as Bz-430, were all higher than that of the solvent-free form (Figure 3). This observation indicates that Bz-423 fills space more efficiently with a solvent molecule present than in pure form. The increased packing efficiency of solvated Bz-423 offers an attractive explanation for why the molecule will not crystallize as a solvent-free form from small-molecule solvents. To explore if this hypothesis
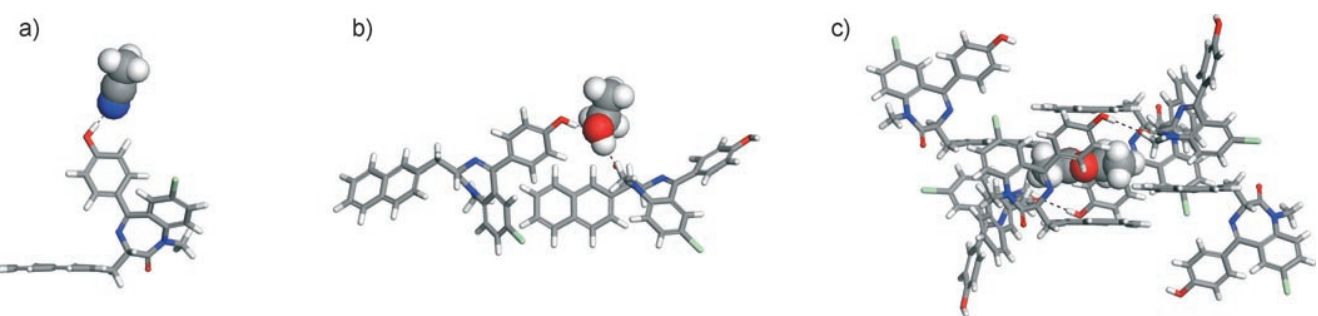

Figure 1. Modes of interaction between Bz-423 and the included a) acetonitrile, b) ethanol, and c) ethyl acetate solvent molecules extracted from the respective crystal structures. 


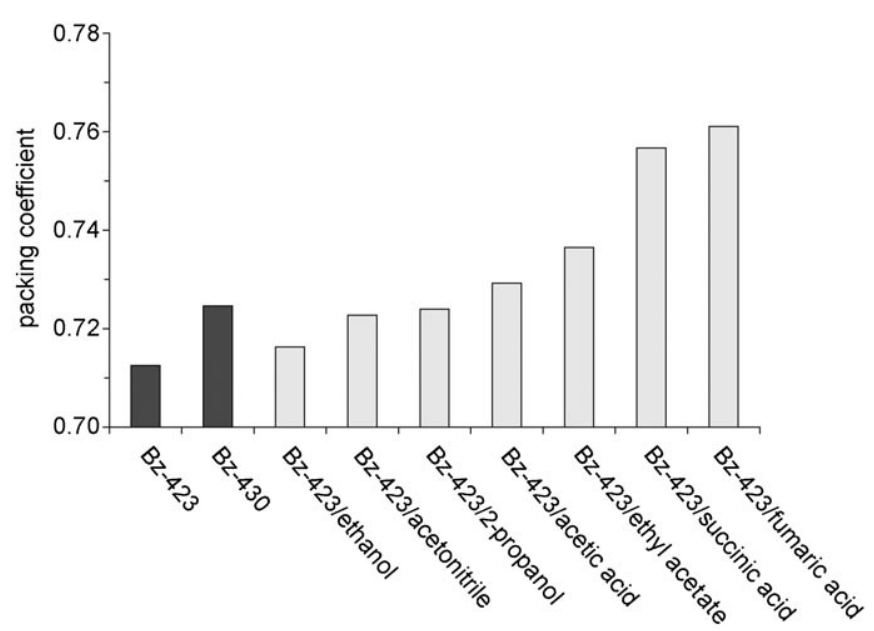

Figure 3. Comparison of the packing coefficients of the Bz-423 solvates, solvent-free $\mathrm{Bz}-423$, and $\mathrm{Bz}-430$. mediate between the more and less dense polymorphs of the solvent-free compound (Figure 5). The presence of relatively close-packed polymorphs for both sulfathiazole and gossypol offers a potential explanation for why, in contrast to Bz-423, these compounds can readily give rise to unsolvated forms.

It is instructive to contrast the behavior of the pharmaceuticals described above with Dianin's compound, a derivative of 1,2-benzopyran that has been studied extensively as a host material. ${ }^{[17-22]}$ This molecule forms isomorphous solvates with a diverse array of solvents, and in each and every structure the solvent resides in the same pocket. A solventfree crystal form of Dianin's compound was obtained from dodecane, a solvent too large to occupy the lattice vacancies. Packing coefficients were calculated for the structures found in the CSD, and the solvates were revealed to pack more efficiently than the solvent-free crystal (Figure 6). Like Bz423, Dianin's compound solvates many different solvents, thus increasing its packing efficiency, but unlike Bz-423 it forms isomorphous structures in all structurally characterized

generally holds for other pharmaceuticals prone to solvate formation, solvent-free and solvated crystal structures of sulfathiazole and gossypol culled from the Cambridge Structural Database (CSD) were analyzed and their packing coefficients were calculated. ${ }^{[15]}$ In both cases, the presence of polymorphism as well as variation of the temperature of the data collection complicates the analysis somewhat. In addition, although there are over 100 solvates/cocrystals of sulfathiazole, few of the crystal structures are available in the CSD. ${ }^{[16]}$ The packing coefficients of the five polymorphs and three solvates were calculated (Figure 4). These solvates pack with efficiencies that are intermediate between the most and least dense solvent-free polymorph of this pharmaceutical. A similar analysis on gossypol, which encompasses two solvent-free polymorphs and 31 solvates, finds that the packing coefficients for all solvates are inter-

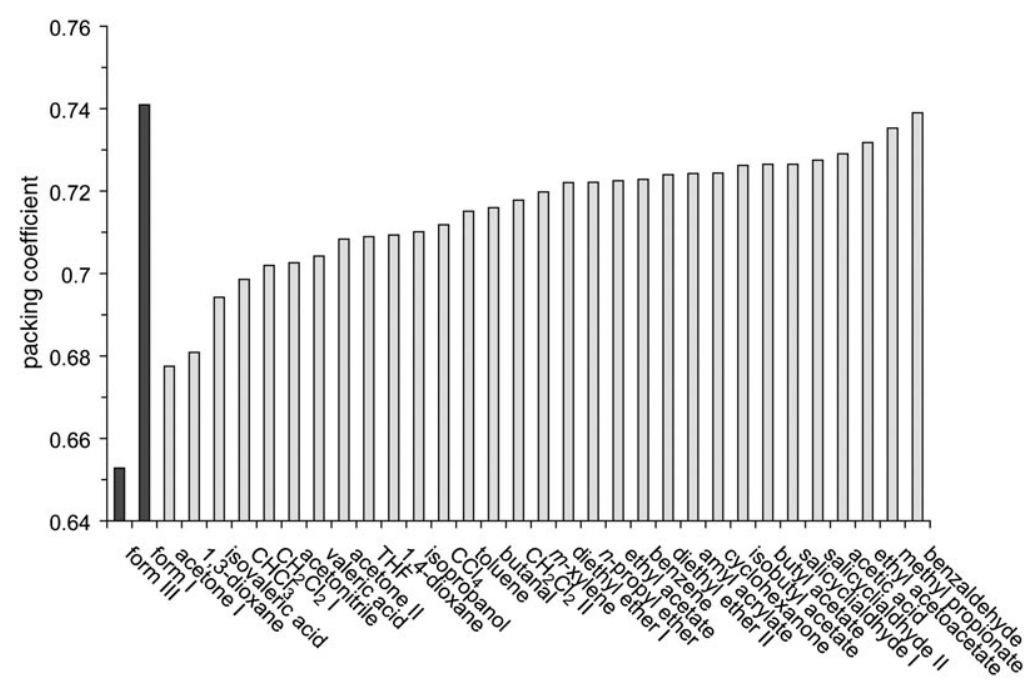

Figure 5. Comparison of the packing coefficients of the gossypol solvates and polymorphs taken from the CSD.

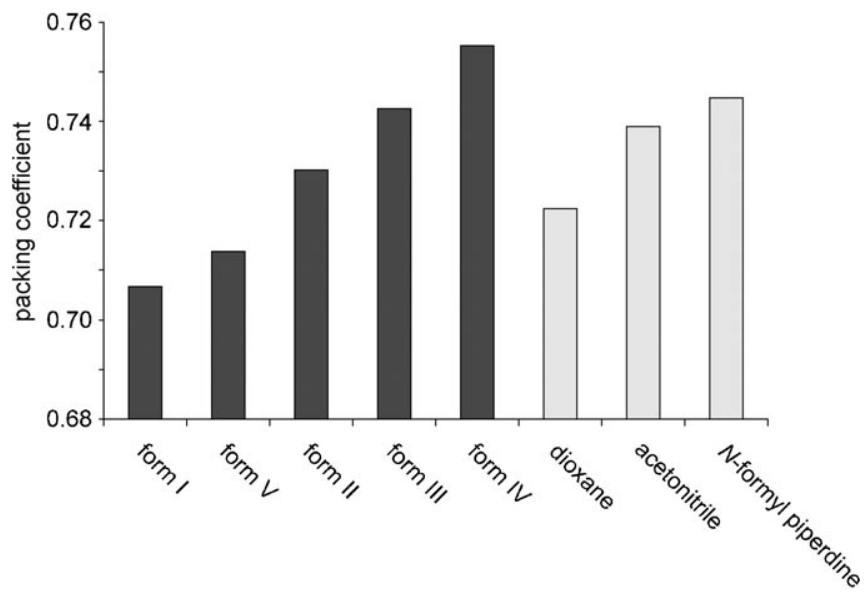

Figure 4. Comparison of the packing coefficients of the sulfathiazole solvates and polymorphs taken from the CSD.

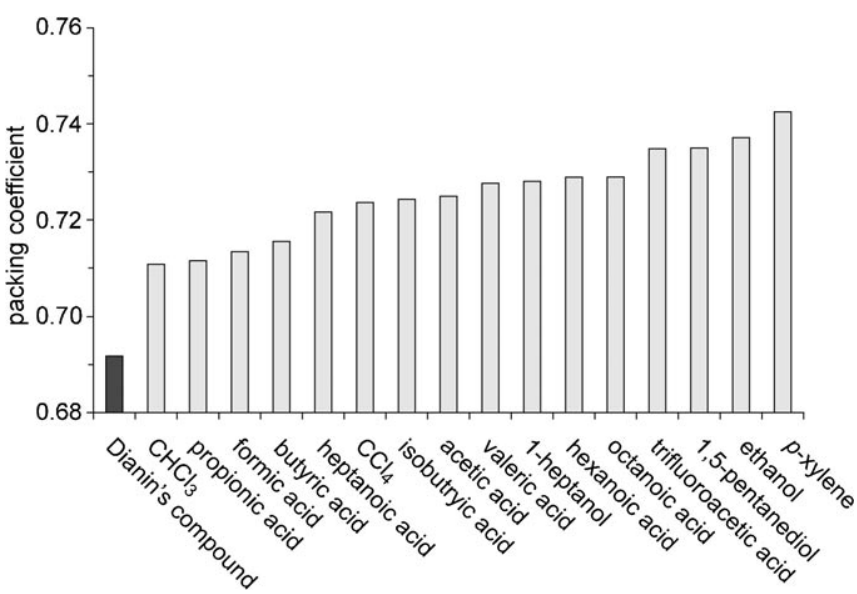

Figure 6. Comparison of the packing coefficients of the Dianin's compound solvates and solvent-free form taken from the CSD. 
solvates. This suggests that the inefficiency of crystal packing for Bz-423 arises from a confluence of multiple small voids rather than a well-defined cavity or channel structure. Predicting such behavior in new compounds will require a comparison to reference packing coefficients derived from data for structural relatives. This approach will aid in the evaluation of the tendency of a particular compound to form solvates. ${ }^{[23]}$

Received: October 5, 2005

Published online: February 22, 2006

Keywords: benzodiazepines · packing efficiency .

solid-state structures · solvates · supramolecular chemistry

[1] For recent examples of studies that employ crystal engineering of pharmaceutical solvates/cocrystals, see: a) I. D. H. Oswald, D. R. Allan, P. A. McGregor, W. D. S. Motherwell, S. Parsons, C. R. Pulham, Acta Crystallogr. Sect. B 2002, 58, 1057-1066; b) R. D. B. Walsh, M. W. Bradner, S. Fleischman, L. A. Morales, B. Moulton, N. Rodríguez-Hornedo, M. J. Zaworotko, Chem. Commun. 2003, 186-187; c) J. F. Remenar, S. L. Morissette, M. L. Peterson, B. Moulton, J. M. MacPhee, H. R. Guzmán, Ö. Almarsson, J. Am. Chem. Soc. 2003, 125, 8456-8457; d) S. G. Fleischman, S. S. Kuduva, J. A. McMahon, B. Moulton, R. D. B. Walsh, N. Rodríguez-Hornedo, M. J. Zaworotko, Cryst. Growth Des. 2003, 3, 909-919; e) Ö. Almarsson, M. B. Hickey, M. L. Peterson, S. L. Morissette, S. Soukasene, C. McNulty, M. Tawa, J. M. MacPhee, J. F. Remenar, Cryst. Growth Des. 2003, 3, $927-$ 933; f) S. L. Childs, L. J. Chyall, J. T. Dunlap, V. N. Smolenskaya, B. C. Stahly, G. P. Stahly, J. Am. Chem. Soc. 2004, 126, $13335-$ 13342 ; g) J. A. McMahon, J. A. Bis, P. Vishweshwar, T. R. Shattock, O. L. McLaughlin, M. J. Zaworotko, Z. Kristallogr. 2005, 220, 340-350; h) A. V. Trask, W. D. S. Motherwell, W. Jones, Cryst. Growth Des. 2005, 5, 1013-1021.

[2] G. J. Kruger, G. Gafner, Acta Crystallogr. Sect. B 1971, 27, 326333.

[3] G. J. Kruger, G. Gafner, Acta Crystallogr. Sect. B 1972, 28, $272-$ 283.

[4] F. V. Babilev, V. K. Bel'skii, Y. A. Simonov, A. P. Arzamastsev, Khim. Farm. Zh. 1987, 21, 1275-1280.

[5] D. S. Hughes, M. B. Hursthouse, T. Threlfall, S. Tavener, Acta Crystallogr. Sect. C 1999, 55, 1831-1833.

[6] A. L. Bingham, D. S. Hughes, M. B. Hursthouse, R. W. Lancaster, S. Tavener, T. L. Threlfall, Chem. Commun. 2001, 603-604.

[7] M. Gdaniec, B. T. Ibragimov, S. A. Talipov in Comprehensive Supramolecular Chemistry, Vol. 6 (Eds.: D. D. MacNicol, F. Toda, R. Bishop), Elsevier Sciences, London, 1996, pp. 117-145.

[8] N. B. Blatt, J. J. Bednarski, R. E. Warner, F. Leonetti, K. M. Johnson, A. Boitano, R. Yung, B. C. Richardson, K. J. Johnson, J. A. Ellman, A. W. Opipari, G. D. Glick, J. Clin. Invest. 2002, $110,1123-1132$.

[9] J. J. Bednarski, R. E. Warner, T. Rao, F. Leonetti, R. Yung, B. C. Richardson, K. J. Johnson, J. A. Ellman, A. W. Opipari, G. D. Glick, Arthritis Rheum. 2003, 46, 757-766.

[10] K. M. Johnson, X. N. Chen, A. Boitano, L. Swenson, A. W. Opipari, G. D. Glick, Chem. Biol. 2005, 12, 485-496.

[11] Crystal data: a) solvent-free $\mathrm{Bz}-423 ; \mathrm{C}_{27} \mathrm{H}_{21} \mathrm{ClN}_{2} \mathrm{O}_{2}$, colorless plate crystal of dimensions $0.28 \times 0.20 \times 0.04 \mathrm{~mm}$ was analyzed at 123(2) K, orthorhombic, space group Pbca (no. 61), $a=$ 14.835(3), $\quad b=14.999(3), \quad c=19.901(4) \AA, \quad V=4528.4(14) \AA^{3}$, $Z=8, \quad \rho_{\text {calcd }}=1.323 \mathrm{~g} \mathrm{~cm}^{-3}, \quad \mu\left(\mathrm{Mo}_{\mathrm{K} \alpha}\right)=0.200 \mathrm{~mm}^{-1}, \quad F(000)=$ 1840,3789 unique reflections between $2.90^{\circ}<2 \theta<24.81^{\circ}$, $\left.T_{\max }=0.99, T_{\min }=0.95, R_{1}=0.0378, R_{w}=0.0780 ; \quad \mathrm{b}\right) \mathrm{Bz}-430$ :
$\mathrm{C}_{29} \mathrm{H}_{23} \mathrm{ClN}_{2} \mathrm{O}_{2}$ colorless plate crystal of dimensions $0.12 \times 0.04 \times$ $0.02 \mathrm{~mm}$ was analyzed at $123(2) \mathrm{K}$, monoclinic, space group $P 2_{1} /$ $c$ (no. 14), $a=9.7205(8), b=19.3671(17), c=12.8434(10), \beta=$ 104.870(3) $)^{\circ}, \quad V=2336.9(3) \AA^{3}, \quad Z=4, \quad \rho_{\text {calcd }}=1.327 \mathrm{~g} \mathrm{~cm}^{-1}, \mu-$ $\left(\mathrm{Mo}_{\mathrm{K} \alpha}\right)=0.193 \mathrm{~mm}^{-1}, F(000)=967,2554$ unique reflections between $3.02^{\circ} \leq 2 \theta \leq 21.18^{\circ}, R_{1}=0.0424, R_{w}=0.0892$; c) Bz423/acetic acid solvate: $\mathrm{C}_{27} \mathrm{H}_{21} \mathrm{ClN}_{2} \mathrm{O}_{2} \cdot \mathrm{C}_{2} \mathrm{H}_{4} \mathrm{O}_{2}$, colorless plate crystal of dimensions $0.36 \times 0.24 \times 0.10 \mathrm{~mm}$ was analyzed at $123(2) \mathrm{K}$, monoclinic, space group $P 2_{1} / c$ (no. 14), $a=9.261$ (2), $b=13.649(3), c=19.753(4) \AA, \beta=97.623(4)^{\circ}, V=2474.9(9) \AA^{3}$, $Z=4, \quad \rho_{\text {calcd }}=1.345 \mathrm{~g} \mathrm{~cm}^{-3}, \quad \mu\left(\mathrm{Mo}_{\mathrm{K} \alpha}\right)=0.193 \mathrm{~mm}^{-1}, \quad F(000)=$ 1048,4629 unique reflections between $2.97^{\circ} \leq 2 \theta \leq 25.65^{\circ}$, $\left.T_{\max }=0.98, T_{\min }=0.93, R_{1}=0.0428, R_{w}=0.0881 ; \mathrm{d}\right) \mathrm{Bz}-423 / \mathrm{ace}-$ tonitrile solvate: $\mathrm{C}_{27} \mathrm{H}_{21} \mathrm{ClN}_{2} \mathrm{O}_{2} \cdot \mathrm{C}_{2} \mathrm{H}_{3} \mathrm{~N}$, colorless plate crystal of dimensions $0.25 \times 0.14 \times 0.05 \mathrm{~mm}$ was analyzed at $153(2) \mathrm{K}$, monoclinic, space group $P 2_{1} / c$ (no. 14), $a=9.310(11), b=$ 13.7802(17), $c=19.082(2) \AA, \beta=93.634(2)^{\circ}, V=2443.2(5) \AA^{3}$, $Z=4, \rho_{\text {calcd }}=1.310 \mathrm{~g} \mathrm{~cm}^{-3}, \mu\left(\mathrm{Mo}_{\mathrm{K} \alpha}\right)=0.181 \mathrm{~mm}^{-1}, F(000)=920$, 5610 unique reflections between $1.82^{\circ} \leq 2 \theta \leq 27.51^{\circ}, T_{\max }=0.99$, $T_{\min }=0.96, R_{1}=0.0352, R_{w}=0.0976$; e) Bz-423/ethanol solvate: $\mathrm{C}_{27} \mathrm{H}_{21} \mathrm{ClN}_{2} \mathrm{O}_{2} \cdot \mathrm{C}_{2} \mathrm{H}_{6} \mathrm{O}$, colorless plate crystal of dimensions $0.32 \times 0.18 \times 0.08 \mathrm{~mm}$ was analyzed at $153(2) \mathrm{K}$, orthorhombic, space group $P b c a$ (no. 61), $a=14.7352$ (11), $b=15.3206(11), c=$ 22.1937(17) $\AA, V=5010.3(6) \AA^{3}, Z=8, \rho_{\text {calcd }}=1.291 \mathrm{~g} \mathrm{~cm}^{-3}, \mu$ $\left(\mathrm{Mo}_{\mathrm{K} a}\right)=0.186 \mathrm{~mm}^{-1}, F(000)=2048,5769$ unique reflections between $1.84^{\circ} \leq 2 \theta \leq 27.57^{\circ}, T_{\max }=0.98, T_{\min }=0.96, R_{1}=0.0901$, $R_{w}=0.2224 ; \quad$ f) $\mathrm{Bz}-423 /$ ethyl acetate solvate $2 \mathrm{C}_{27} \mathrm{H}_{21} \mathrm{ClN}_{2} \mathrm{O}_{2} \cdot \mathrm{C}_{4} \mathrm{H}_{8} \mathrm{O}_{2}$ : colorless block crystal of dimensions $0.50 \times 0.26 \times 0.14 \mathrm{~mm}$ was analyzed at $123(2) \mathrm{K}$, monoclinic, space group $P 2_{1} / n$ (no. 14), $a=16.208(2) b=9.2803(12), c=$ 16.937(2) $\AA, \quad \beta=110.161(2)^{\circ}, \quad V=2391.5(5) \AA^{3}, Z=4, \quad \rho_{\text {calcd }}=$ $1.347 \mathrm{~g} \mathrm{~cm}^{-3}, \quad \mu\left(\mathrm{Mo}_{\mathrm{K} \alpha}\right)=0.195 \mathrm{~mm}^{-1}, \quad F(000)=1020, \quad 5930$ unique reflections between $3.07^{\circ} \leq 2 \theta \leq 28.30^{\circ}, \quad T_{\max }=0.97$, $\left.T_{\min }=0.91, R_{1}=0.0350, R_{w}=0.0933 ; \mathrm{g}\right) \mathrm{Bz}-423 /$ fumaric acid cocrystal: $2 \mathrm{C}_{27} \mathrm{H}_{21} \mathrm{ClN}_{2} \mathrm{O}_{2} \cdot \mathrm{C}_{4} \mathrm{H}_{4} \mathrm{O}_{4}$, colorless plate crystal of dimensions $0.30 \times 0.24 \times 0.08 \mathrm{~mm}$ was analyzed at $123(2) \mathrm{K}$, monoclinic, space group $P 2_{1} / c$ (no. 14), $a=9.0653(13), b=$ 13.7215(19), $c=18.753(3) \AA, \beta=93.236(3)^{\circ}, V=2329.0(6) \AA^{3}$, $Z=4, \quad \rho_{\text {calcd }}=1.423 \mathrm{~g} \mathrm{~cm}^{-3}, \quad \mu\left(\mathrm{Mo}_{\mathrm{K} \alpha}\right)=0.205 \mathrm{~mm}^{-1}, \quad F(000)=$ 1040,5797 unique reflections between $2.86^{\circ} \leq 2 \theta \leq 28.37^{\circ}$, $\left.T_{\max }=0.98, T_{\min }=0.94, R_{1}=0.0412, R_{w}=0.0886 ; \mathrm{h}\right) \mathrm{Bz}-423 / 2-$ propanol solvate: $\mathrm{C}_{27} \mathrm{H}_{21} \mathrm{ClN}_{2} \mathrm{O}_{2} \cdot \mathrm{C}_{3} \mathrm{H}_{8} \mathrm{O}$, colorless plate crystal of dimensions $0.40 \times 0.36 \times 0.12 \mathrm{~mm}$ was analyzed at $123(2) \mathrm{K}$, orthorhombic, space group Pbca (no. 61), $a=14.418(3), b=$ $15.779(3), c=22.625(4) \AA, \quad V=5147.3(16) \AA^{3}, \quad Z=8, \quad \rho_{\text {calcd }}=$ $1.293 \mathrm{~g} \mathrm{~cm}^{-3}, \quad \mu\left(\mathrm{Mo}_{\mathrm{Ka}}\right)=0.183 \mathrm{~mm}^{-1}, \quad F(000)=2112, \quad 4420$ unique reflections between $2.11^{\circ} \leq 2 \theta \leq 24.78^{\circ}, \quad T_{\max }=0.98$, $T_{\min }=0.93, R_{1}=0.0339, R_{w}=0.0805 ;$ i) Bz-423/succinic acid cocrystal: $2 \mathrm{C}_{27} \mathrm{H}_{21} \mathrm{ClN}_{2} \mathrm{O}_{2} \cdot \mathrm{C}_{4} \mathrm{H}_{6} \mathrm{O}_{4}$, colorless plate block of dimensions $0.44 \times 0.22 \times 0.20 \mathrm{~mm}$ was analyzed at $123(2) \mathrm{K}$, monoclinic, space group $P 2_{1} / c$ (no. 14), $a=9.1098(14), b=$ 13.834(2), $\quad c=18.715(2) \AA, \quad \beta=92.223(3)^{\circ}, \quad V=2356.8(6) \AA^{3}$, $Z=4, \quad \rho_{\text {calcd }}=1.409 \mathrm{~g} \mathrm{~cm}^{-3}, \quad \mu\left(\mathrm{Mo}_{\mathrm{K} \alpha}\right)=0.203 \mathrm{~mm}^{-1}, \quad F(000)=$ 1044, 5860 unique reflections between $2.86^{\circ} \leq 2 \theta \leq 28.40^{\circ}$, $T_{\max }=0.96, T_{\min }=0.92, R_{1}=0.0335, R_{w}=0.0882$. Intensity data were collected on a Bruker SMART CCD-based X-ray diffractometer $\left(\mathrm{Mo}_{\mathrm{K} \alpha}=0.71073 \AA\right)$. The structures were solved by direct methods and refined using the SHELXTL (v6.10 for structures (d) and (e) and v6.12 for all others) software package. All non-hydrogen atoms were refined anisotropically with hydrogen atoms generated at idealized positions and constrained to ride on their parent atoms. CCDC-285005-285013 contain the supplementary crystallographic data for this paper. These data can be obtained free of charge from The Cambridge Crystallographic Data Centre via www.ccdc.cam.ac.uk/data_request/cif.

[12] A. I. Kitaigorodskii, Organic Chemical Crystallography, Consultants Bureau, New York, 1961. 
[13] Packing coefficient is calculated by using the following equation: $C_{\mathrm{k}}=Z V_{\text {mol }} V_{\text {cell }}^{-1}$, where $V_{\text {mol }}$ is the molecular volume $\left(\AA^{3}\right), V_{\text {cell }}$ is the volume of the unit cell $\left(\AA^{3}\right)$, and $Z$ is the number of molecules in the unit cell.

[14] Molecular volume was calculated with Spartan'04 (Wavefunction Inc.), which employs van der Waals radii in the calculation of molecular volume of $1.75 \AA$ for carbon, $1.78 \AA$ for chlorine, $1.30 \AA$ for fluorine, $1.20 \AA$ for hydrogen, $1.55 \AA$ for nitrogen, $1.52 \AA$ for oxygen, and $1.82 \AA$ for sulfur atoms. For the packing efficiency of the crystal structures of sulfathiazole solvates not found in the CSD (see reference [16]) and for disordered solvate structures, models of sulfathiazole and the various solvent molecules were constructed in Spartan '04 and the equilibrium geometry for each was calculated by using molecular mechanics (MMFF). After geometric minimization, the $\mathrm{C}-\mathrm{H}, \mathrm{N}-\mathrm{H}$, and $\mathrm{O}-\mathrm{H}$ bonds were normalized to $1.083 \AA$ for $\mathrm{C}-\mathrm{H}$ and $0.983 \AA$ for $\mathrm{O}-\mathrm{H}$ and $\mathrm{N}-\mathrm{H}$ and the molecular volume was calculated. A list of the structures that possess disordered solvent molecules can be found in the Supporting Information.

[15] Crystal structures of two-component systems containing organic solvent molecules (liquid under ambient conditions) and possessing 3D coordinates were selected from the CSD for each compound. The $\mathrm{C}-\mathrm{H}, \mathrm{O}-\mathrm{H}$, and $\mathrm{N}-\mathrm{H}$ bonds in each structure were normalized and the molecular volume was calculated (see reference [14]). CSD reference codes for the structures used in the paper: sulfathiazole, SUTHAZ01, SUTHAZ02, SUTHAZ03, SUTHAZ04, SUTHAZ05, BABYIN, BABYOT, and FURDIF; gossypol, AWEXUV, BEMLOU03, BEMLOU12, CUVKEJ20, CUVKUZ20, CUVLAG10, DUBVUR, GOSPOL01, JEGWAT, JIDROD, JIDTIZ10, JIDTOF01，JIDTOF10，JIDVEX10，JIDWEY01，JINFAN, KIVCAT, LOQSEP, RIDNOH, RIDNUN, VAYJUA, VEVMOY, VEVNUF01, VEVRIX, VEVROD, VEVRUJ, VEVSEU, VEVTOF, VEVVUN01, VEVWUO, VEVXAV, VIGVUC, and YEWMUI; Dianin's compound, BEGSUC, DIANCH, DIANET, DIANHP13, HUSXOI, HUSXUO, HUSYAV, HUSYEZ, HUSYID, HUSYOJ, HUSYUP, HUSZAW, HUSZEA, HUSZIE, OBEQUH, PEPTIN, and SIHJEY01; references for these can be found in the Supporting Information.

[16] For a number of sulfathiazole solvates not found in the CSD, unit-cell constants, and stoichiometry have been reported; see the Supporting Information of reference [6]. The packing coefficients for the acetone, cyclohexanol, cyclohexanone, piperidine, propionitrile, propylene carbonate, sulfolane, and THF solvates were calculated from these data with the caveat that the geometries of both sulfathiazole and the solvent must be assumed, thus making these values somewhat less reliable than those derived from 3D structures. The calculated packing coefficients of these structures range from 0.684 (cyclohexanol) to 0.746 (sulfolane), with an average value of 0.713 , which is intermediate to the packing coefficients of the most and least dense polymorphs of sulfathiazole.

[17] J. L. Flippen, J. Karle, I. L. Karle, J. Am. Chem. Soc. 1970, 92, $3749-3754$.

[18] L. Pang, E. A. C. Lucken, G. Bernardinelli, J. Am. Chem. Soc. 1990, 112, 8754-8764.

[19] F. Imashiro, M. Yoshimura, T. Fujiwara, Acta Crystallogr. Sect. C 1998, 54, $1357-1360$.

[20] G. D. Enright, C. I. Ratcliffe, J. A. Ripmeester, Mol. Phys. 1999, 97, 1193-1196.

[21] J. G. Selbo, J. M. Desper, C. J. Eckhardt, J. Inclusion Phenom. Macrocyclic Chem. 2003, 45, 73-78.

[22] R. W. H. Small, Acta Crystallogr. Sect. B 2003, 59, 141-148.

[23] For rigid molecules, the packing coefficient may be conveniently extracted from the cell parameters and a knowledge of the chemical structure facilitating prescreening studies utilizing only indexed powder X-ray diffraction data. 